\title{
Assessment-Based Pest Management of German Cockroaches ${ }^{1}$
}

\author{
F.M. Oi, E. Weeks, J. Jonovich, and D. Miller²
}

Integrated pest management (IPM) has been misunderstood and consequently has suffered from poor adoption, even though the concept has demonstrated success. We use the term "assessment-based" pest management (APM), coined by D. Miller, to emphasize the importance of evaluating the intensity of the pest problem and concomitant conducive conditions before treatment is attempted.

Assessment-based pest management honors the principles of IPM. The decision flow chart (Figure 1) is intended to provide an overview on how German cockroaches can be managed with specific guidance for each of the four levels within the publication. The four levels can be viewed as an escalation protocol that may also approximate the tiers in a LEED (Leadership in Energy and Environmental Design) pest management plan and some of the levels may meet the requirements of some "green" pest management certification programs.

\section{Facts You Can Use in Devising Your German Cockroach Assessment- Based Management Strategy}

- Determine the source.

- German cockroaches do not enter structures from outdoors.

- They are spread entirely by humans and live only in association with people.
- German cockroaches are among the most prolific cockroach species, producing 3 to 6 generations per year.

- One ootheca (egg case) contains between 30 to 40 nymphs. Thus, one gravid female is cause for pest control intervention.

- In her lifetime, a female may produce:

- About 1 ootheca per month.

- ootheca in her lifetime.

- Between 240 to 320 offspring.

- German cockroaches prefer to spend most of their lives in cracks and crevices near sources of food and water.

- If cockroaches are seen in the open during the daytime, there is a high probability that the population is large and will require multiple control tactics.

- German cockroaches are used by health departments as a sign of poor sanitation and may result in a failed health inspection.

- German cockroaches produce at least one dozen distinct allergens that are potent triggers of asthma.

- The link to transmission of disease-causing pathogens is not as strong as the link to asthma.

- Baiting, insect growth regulators (IGRs), and vacuums with high-efficiency particulate air filters-(HEPA) are the most effective treatment options for cockroach suppression.

1. This document is ENY989, one of a series of the Entomology and Nematology Department, UF/IFAS Extension. Original publication date December 2017. Visit the EDIS website at http://edis.ifas.ufl.edu.

2. F.M. Oi, director, Pest Management University, and associate Extension scientist, Entomology and Nematology Department, UF/IFAS Extension; E. Weeks, assistant research scientist, Entomology and Nematology Department, UF/IFAS Extension; J. Jonovich, Intellico Solutions and Pest Management University Program Coordinator; and D. Miller, professor, Virginia Polytechnic Institute, Department of Entomology. 


\section{IPM DECISION FLOW CHART}

Use the following flow chart to help guide decisions concerning German cockroach control.

More information about Specific Approaches can be found on the following page.

NO INFESTATION. Proactively perform initial inspection and develop a written IPM plan.

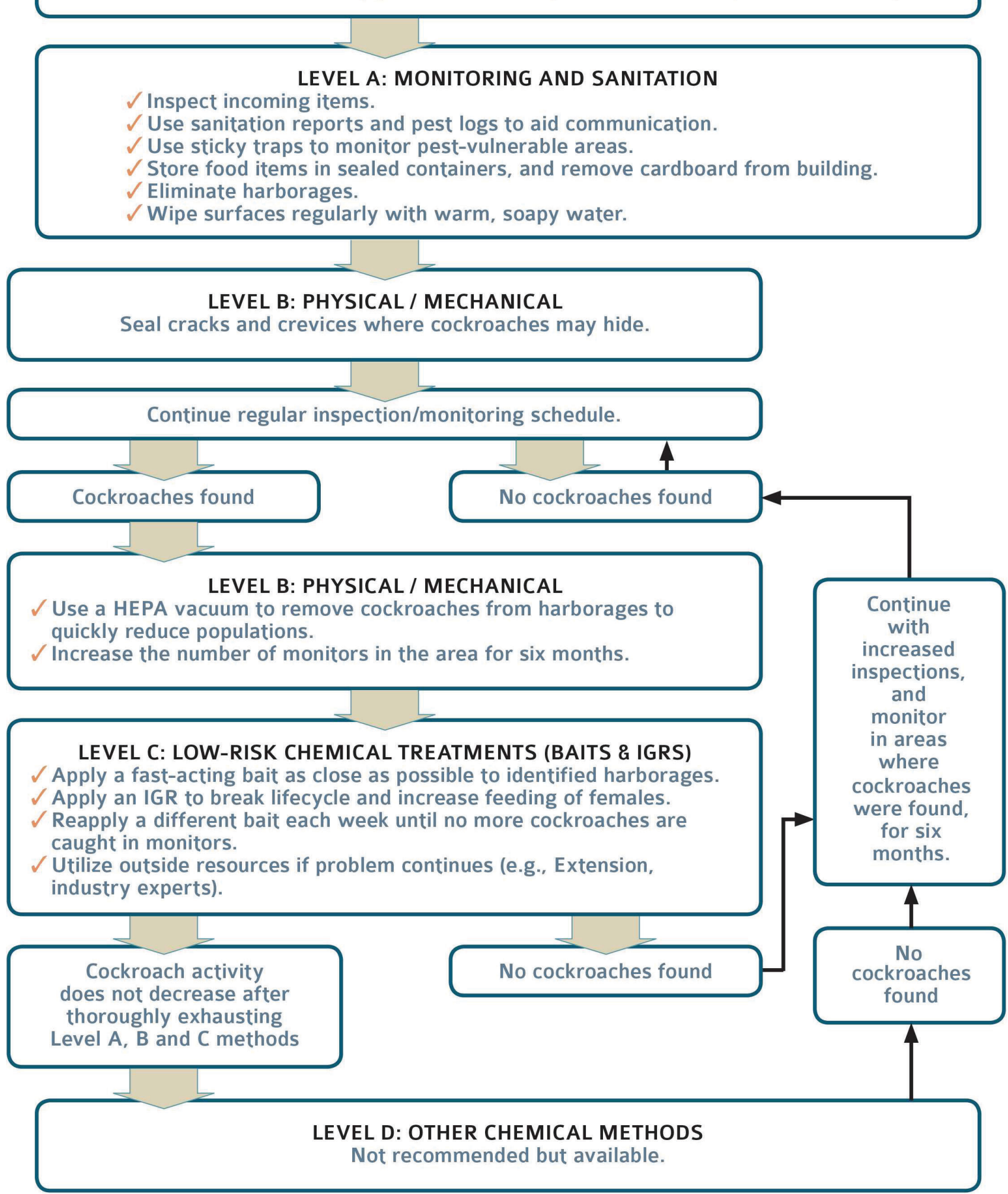

Figure 1. IPM Decision Flow Chart. Levels A, B, C, and D can be considered an escalation protocol. Staying within levels A, B, and possibly C, may be acceptable to "green" programs. 


\section{Description}

- Size: Adults are $1 / 2$ to $5 / 8$ inches long with wings; nymphs vary in size and are wingless

- Color: Light brown to tan

- Key Characters:

- Two dark stripes on the pronotum (shield) behind the head (Figure 2)

- Females can be seen carrying a yellowish-brown ootheca (egg case) protruding from the end of the abdomen. (Figure 3)

- Nymphs are generally darker with two prominent dark stripes surrounding a lighter, tan spot or stripe on body thorax (Figure 4).

\section{Specific Approaches of a German Cockroach Assessment-Based} Management Strategy

\section{Level A-Prevention: Inspection, Monitoring, and Sanitation INSPECTION}

- Prevent infestations by inspecting incoming items for German cockroaches and other pests.

- Be aware that people can carry German cockroaches into an area on backpacks, purses, and other clothing items.

- Use all your senses when looking for cockroaches. If you cannot see them you might be able to smell their distinctive odor, due to the presence of their feces and pheromones.

- Inspections should focus on pest-vulnerable areas where food and water are present, including food-storage areas.

- Use a flashlight and mirror to help you see in difficult to reach areas (Figure 5)

- Inspection practices should include checking for unsealed openings such as:

- Missing or loose pipe and conduit escutcheon plates (Figure 6).

- Unsealed edges around sinks and cabinets, wallmounted electrical panels, mirrors, light fixtures, fire alarms or emergency lighting.

- Hollow-legged tables and chairs that are not sealed.

- Focus on equipment where heat is generated: behind refrigerators and freezers, ovens, stoves, and electrical junction boxes.

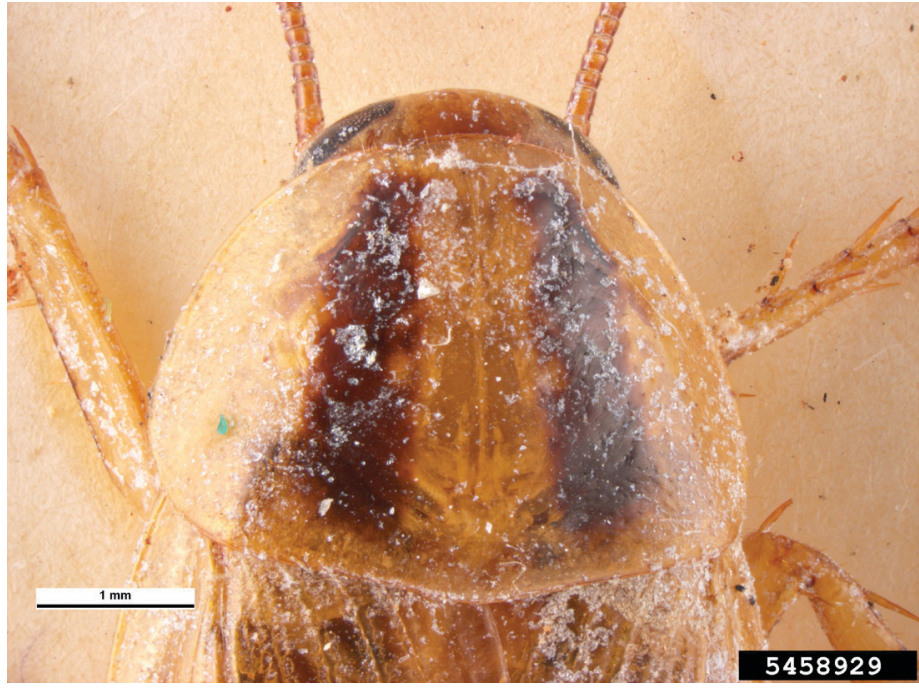

Figure 2. German cockroach female with two stripes on her pronotum (shield).

Credits: Pest and Diseases Image Library, Bugwood.org

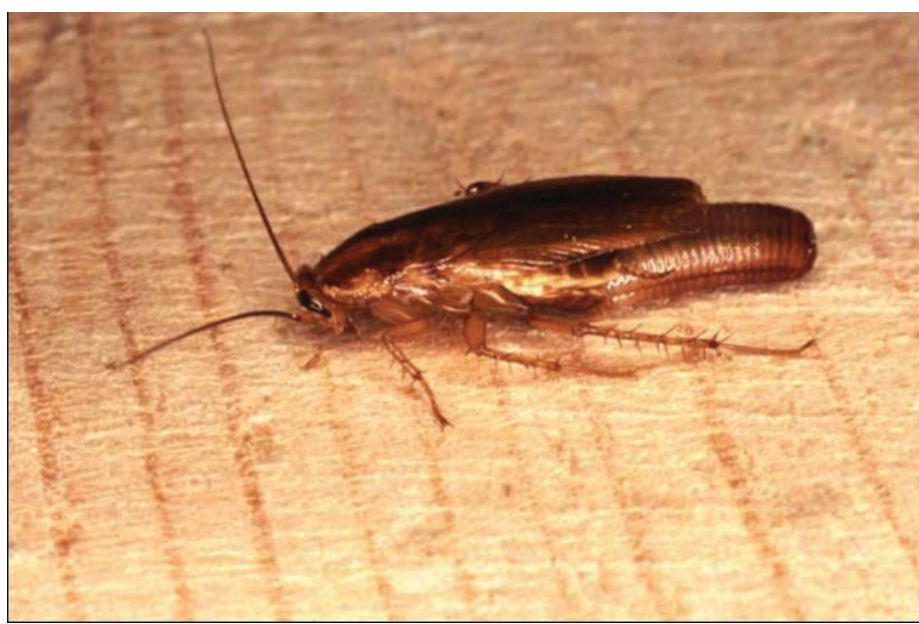

Figure 3. Females can be seen carrying a yellowish-brown ootheca (egg case) protruding from the end of the abdomen.

Credits: J. Castner, UF/IFAS

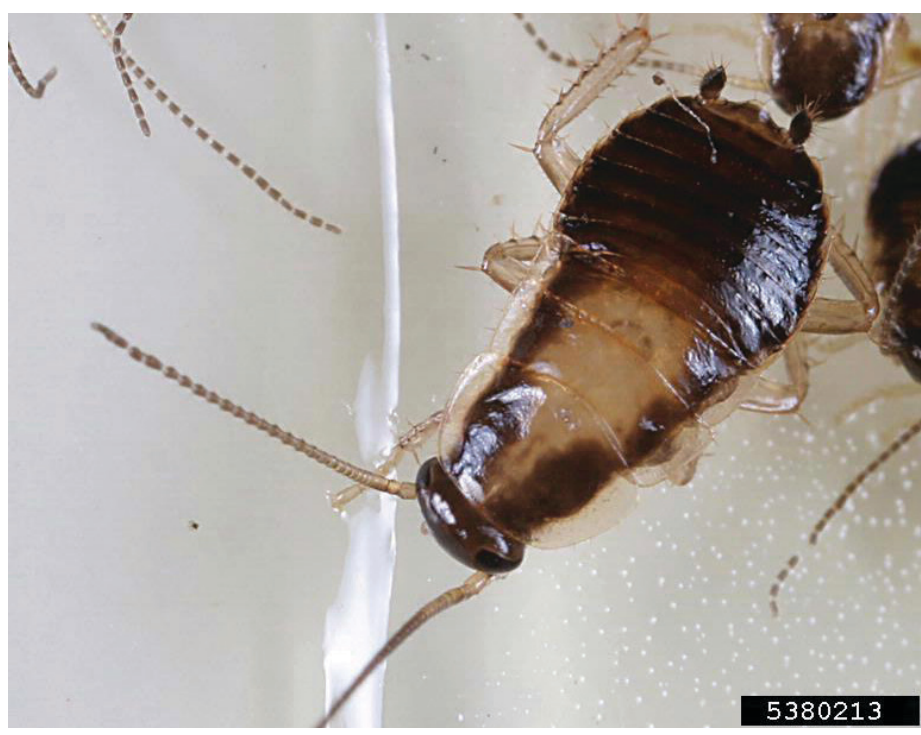

Figure 4. Nymphs are generally darker with two prominent dark stripes surrounding a lighter, tan spot or stripe on body thorax. Credits: Gary Alpert, Harvard University, Bugwood.org 
- If you see cockroaches during the daytime, it may be an indication that you are dealing with an extremely large population (Figure 7).

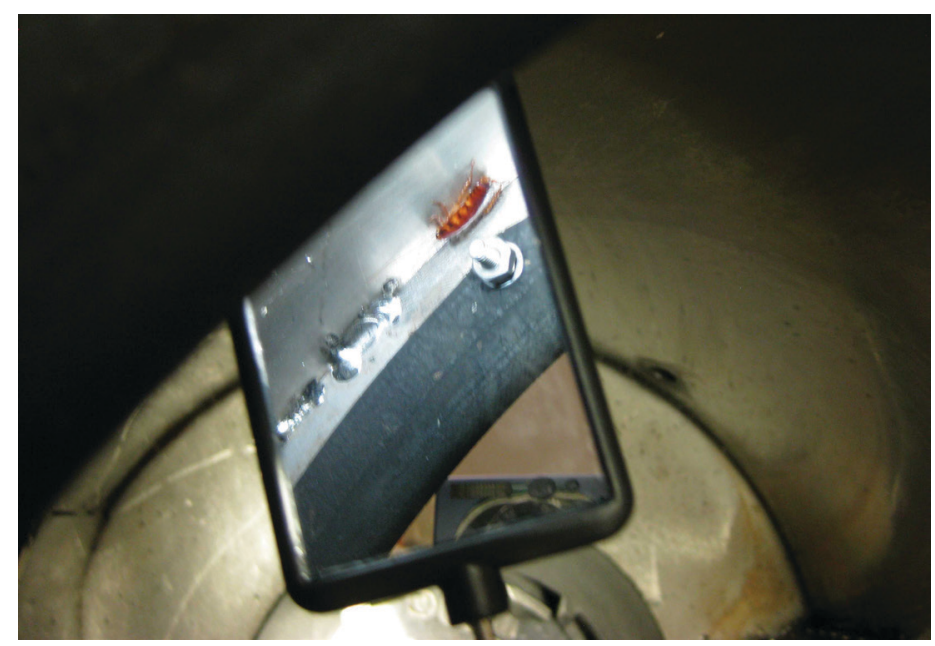

Figure 5. Use an inspection mirror and flashlight to help you see under and around areas that are difficult to reach. Inspection mirrors can be found in any hardware or auto mechanic store.

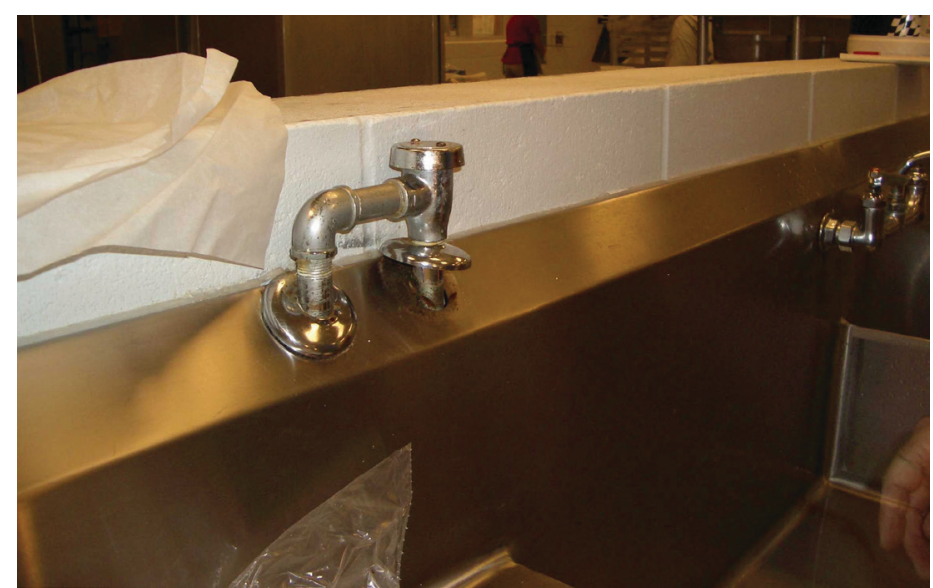

Figure 6. German cockroaches using unsealed escutcheon plates in a cafeteria sink as harborage. Inspection practices should include checking for unsealed openings such as missing or loose pipe and conduit escutcheon plates.

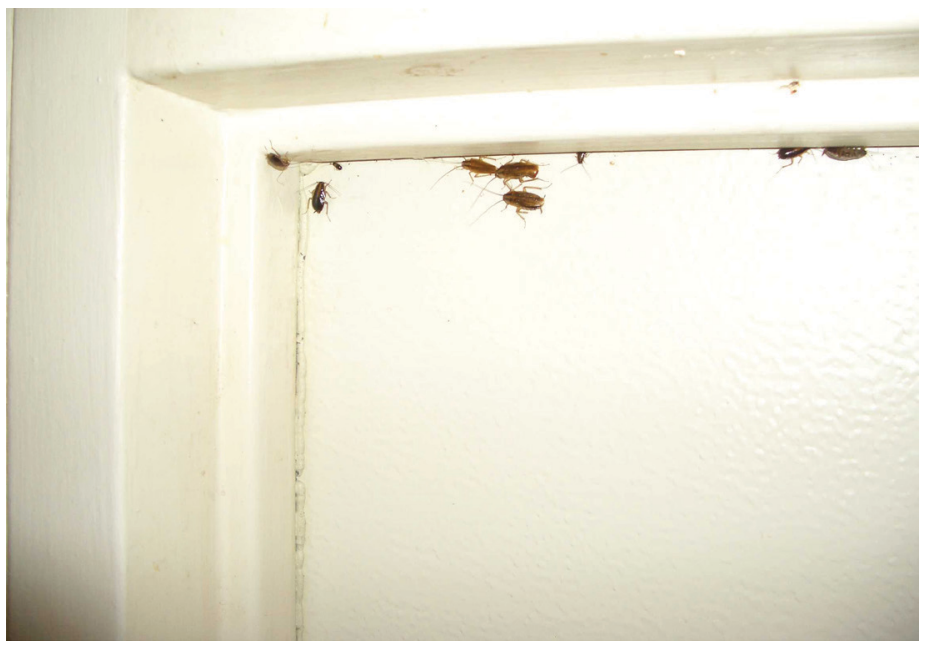

Figure 7. German cockroaches during the daytime, spilling out of cracks and crevices. It may mean that the population is extremely large. Plan management efforts accordingly.

\section{MONITORING}

- Use sticky traps. They are your "eyes" in the property and are working for you 24/7.

- Always date and number monitors for documentation purposes.

- Create a map of the area that includes the location of the numbered monitors. You may also leave space on your map to write numbers of insect per trap for each inspection. It may be helpful to use monitor locators such as stickers (Figure 8a,b)

- Monitors should be replaced if full (sticky area covered), wet, or covered in dust.

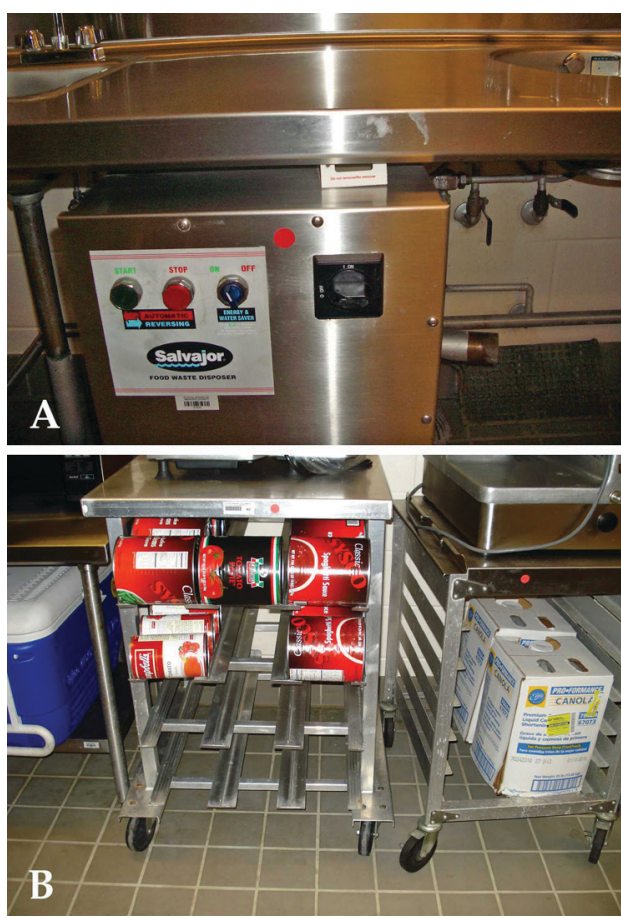

Figure 8. Use visual markers to help you locate monitors that are placed in hidden areas that also are often preferred cockroach harborages. Careful labeling of monitors is important. Always date and number monitors for documentation purposes. Consider drawing a map to help you locate monitors when numerous accounts are involved.

\section{Where are monitors optimally placed?}

- In pest-vulnerable areas including food storerooms and preparation areas, and anywhere else cockroaches have been a problem, including laundry rooms, custodial closets, electrical closets, storage closets, staff lounges, and student lockers.

- In addition to areas with food, water, and harborage, also focus monitor placements near areas where heat is generated. Check behind refrigerators and freezers, ovens, stoves, and electrical junction boxes, as these appliances often attract cockroaches because of the heat they give off. 
- Place monitors in dry areas along structural lines, adjacent to walls, corners etc., where cockroaches travel, and close to suspected cockroach harborages. If they are not placed correctly (Figure 9a), monitors will only trap a fraction of the cockroaches that they otherwise could if placed properly (Figure 9b).
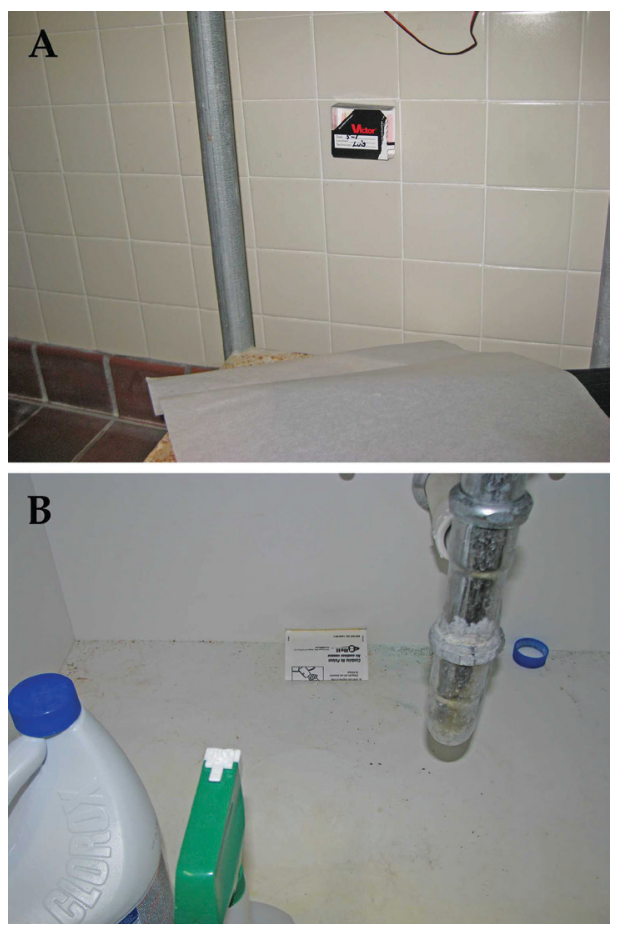

Figure 9. Properly placed versus improperly placed monitors. Placement of sticky traps includes placing monitors in dry areas along structural lines, adjacent to walls, corners etc., where cockroaches travel and close to suspected cockroach harborages.

\section{What kind of information can monitors give me?}

- The presence of all life stages of German cockroaches is an indication that you are dealing with an established infestation (Figure 10).

- One to a few adults indicates that you are most likely dealing with a new introduction.

- Monitors can give you an indication of which direction the cockroach came from in order to better focus inspections.

- A few early instar nymphs may indicate that you should focus your inspection within 5 to 10 feet away from the monitor to identify possible harborages or sources of infestation.

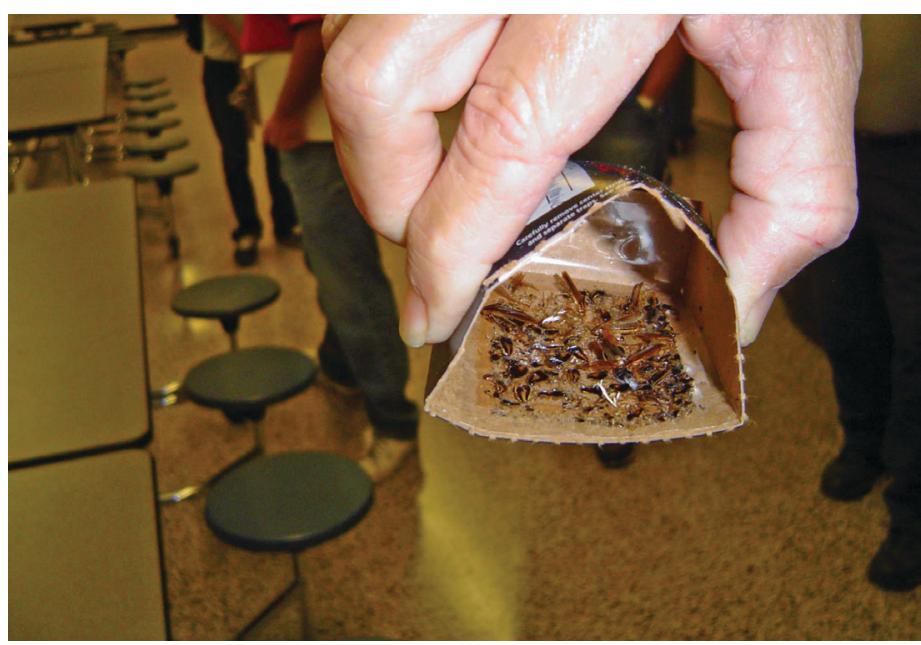

Figure 10. Knowing how to "read" a monitor is critical to IPM success. This monitor contains several stages of nymphs as well as adults, which indicates that there is a severe German cockroach infestation. Monitors can sometimes tell you from what direction the cockroaches are coming, and they are useful during the evaluation process to confirm that your treatment is effective as the number of insects trapped in the monitors decreases.

\section{SANITATION}

Eliminating food, water, and harborage (i.e., the survival triangle) is key to successful German cockroach control (Figure 11).

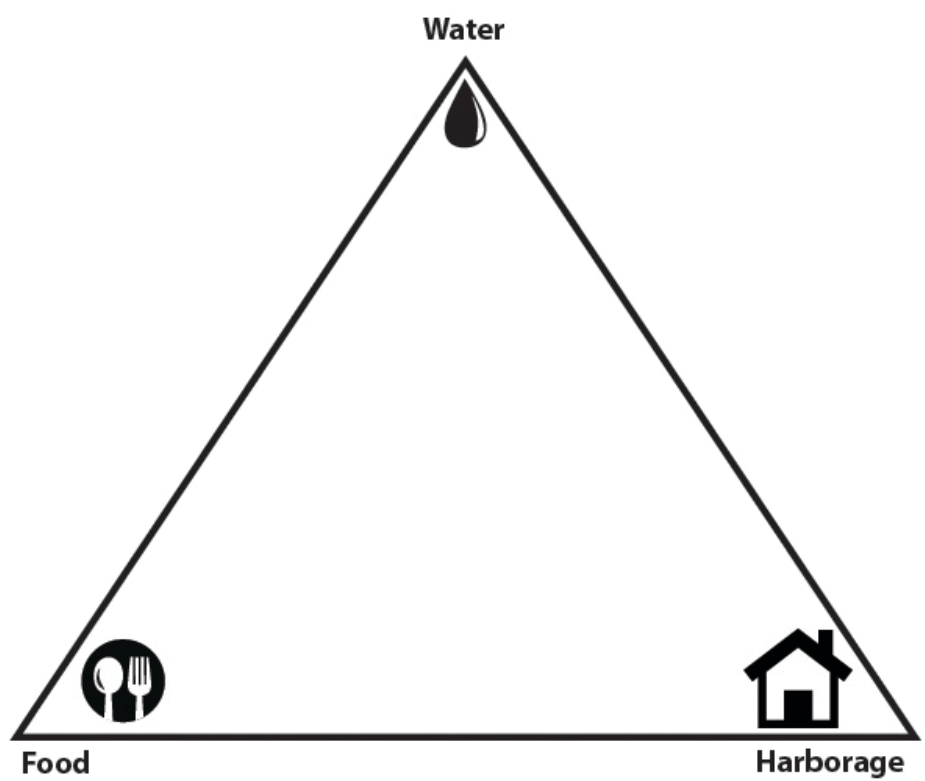

Figure 11. Survival triangle. Eliminate one or all of these factors (e.g., food, water, harborage) to increase pest control success.

\section{General Cleaning}

- Clean often and systematically, paying particular attention to less accessible areas.

- Use soapy water with a clean water rinse to remove cockroach allergens that are potent asthma triggers.

- No-rinse cleaners only spread allergens, they do not remove them. 


\section{Potential Food Sources}

- Store items that cockroaches will eat, including art supplies like corn, beans, and macaroni, in sealed containers (Figure 12).

- Clean up food and drink spills immediately.

- Use thick trashcan liners that will not break easily.

- Empty trashcans containing food at the end of the day.

- Clean drains and cracks and crevices with an enzymebased cleaner.

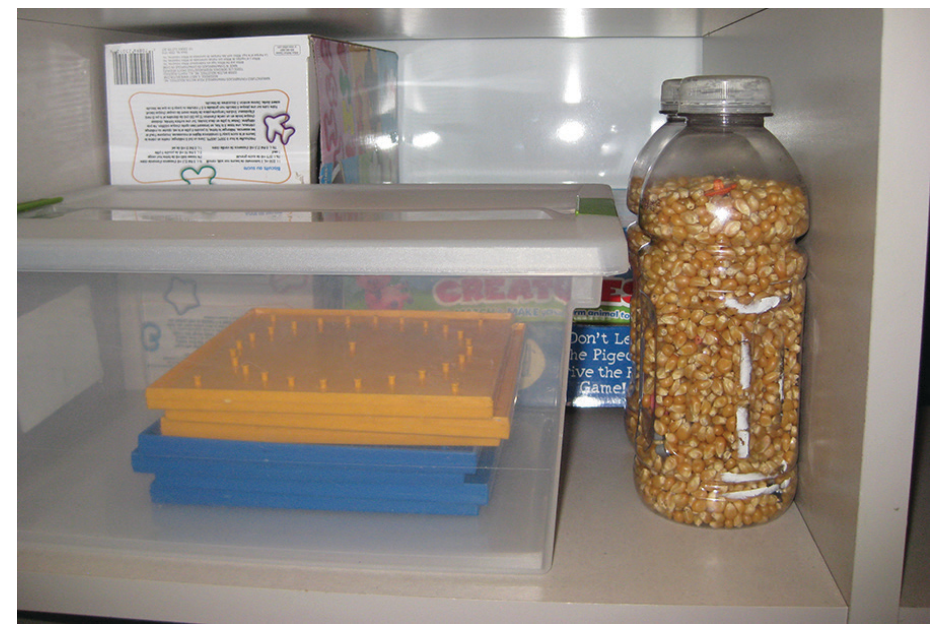

Figure 12. Store any items cockroaches will eat, including art supplies, in sealed containers.

\section{Potential Water Sources}

- Food warmers, ice makers, refrigerators, freezer drains, leaking pipes and faucets, clothes washers, bathrooms.

- Areas with mold growing on walls or ceiling tiles are an indication of an excessive moisture issue.

\section{Potential Harborages}

- Eliminate cardboard. German cockroaches thrive in cardboard.

- Anything requiring storage for $>3$ to 6 months should be stored in plastic bins.

- Eliminate other harborages. Simplify the environment so that cockroaches do not have a place to live and breed. Eliminating harborages also makes inspections and monitoring more efficient.

\section{Level B-Physical/Mechanical Control}

- Eliminate the harborages by sealing cracks. Seal with caulk edges around wall-mounted electrical panels, light fixtures, bulletin boards, sinks, cabinets, etc. Pay particular attention to areas around water and food-preparation sites.
- Use a HEPA vacuum to remove heavy infestations before treatment. This provides immediate control and instant customer satisfaction. It also reduces the infestation to a more manageable level.

- Use a nonchemical flushing agent, such as compressed air in cans used to clean dust from electronics. Direct air stream (often via a straw tip) into cracks and crevices suspected of harboring cockroaches. Vacuum up cockroaches as they emerge. Avoid the use of insecticide flushing agents because they will contaminate bait placements.

\section{Level C-Reduced Exposure Treatments}

The preferred chemical management options for German cockroaches are insecticide baits and IGRs. Chemical options, including baits, should NOT be used on a routine or calendar-basis. Baits and IGRs decrease the probability of unnecessary pesticide exposure compared to surface sprays of contact insecticides. Use product when:

- Cockroach presence has been confirmed through monitoring or inspection and non-chemical measures are also implemented.

- There is a historical reason to apply product, such as a dry storage area where repeated introductions can occur.

Pesticide formulations are a mixture of the active and inert ingredients. Formulations are used to improve the handling, storage, application, effectiveness, and safety of the product.

- Cockroach bait formulations include:

- Gels

- Liquids

- Dry-flowables

\section{WHY USE BAITS?}

- Baits exploit natural cockroach behaviors of:

- Coprophagy-eating feces

- Emetophagy - eating vomit

- Cannibalism-eating each other

- If bait is consumed, the above behaviors confer a certain degree of secondary transfer (or horizontal transfer) when their feces, vomit, or dead bodies are eaten by other cockroaches, increasing the treatment efficacy of baits as compared to surface and baseboard sprays.

- First-stage nymphs do not leave their harborages, which may be in wall voids or behind appliances, to feed. They feed through coprophagy. This is one reason why surface or baseboard sprays do not result 
in $100 \%$ control of cockroaches in a timely way and can result in complaints and "call-backs" after treatment.

- Some modern baits work as quickly as liquid residual spray products and are more effective. This eliminates the need to do a "clean-out" spray, which is a broadcast application of a residual insecticide that is usually repellent.

- The preparation and cleaning required after "cleanout" sprays also are eliminated, saving hours of labor by kitchen staff.

\section{HOW OFTEN SHOULD I BAIT?}

- Frequency of baiting should be determined by the level of the infestation. Follow the label directions. Depending on the level and infestation and product used, bait applications may be reapplied every 1 to 2 weeks to replace any bait that was consumed and to keep fresh bait constantly available. Fresh bait is more palatable to cockroaches.

- Continue placing bait until the number of cockroaches caught on the monitors is reduced to zero with no nymphs or egg cases reported. At this point baiting can end.

- When repeat applications are necessary, rotate your product. Apply a bait with an active ingredient from a different insecticide class at least monthly. (See Table 1 and Product Rotation section below for details). Product rotation will slow the buildup of product resistance.

- Even though new baits are extremely effective when competing food is present, sanitation efforts will be beneficial by improving access to potential harborages for inspection and control efforts.

\section{BAITING TIPS}

- Place baits according to the product label.

- Use information from the monitors to increase effectiveness and efficiency. If the monitors in a room do not contain cockroaches, it is probably not necessary to apply any product.

- If monitors indicate activity in just one part of a room, bait that section of the room.

- Follow the label for application directions. Do not use bait as if it were caulk (Figure 13). Scale the amount of bait used in an account based on the number of cockroaches trapped.

- Keep your bait stored separately from other products that might contaminate it, making the bait unpalatable (Figure $14)$.

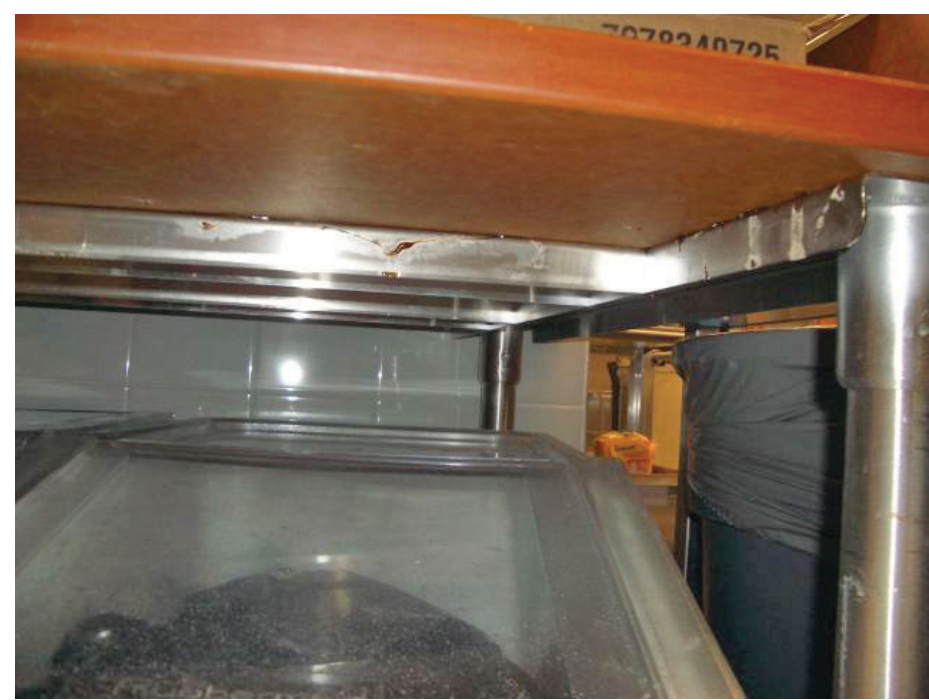

Figure 13. Do not use bait as if it were caulk. Follow label directions on application and number of placements.

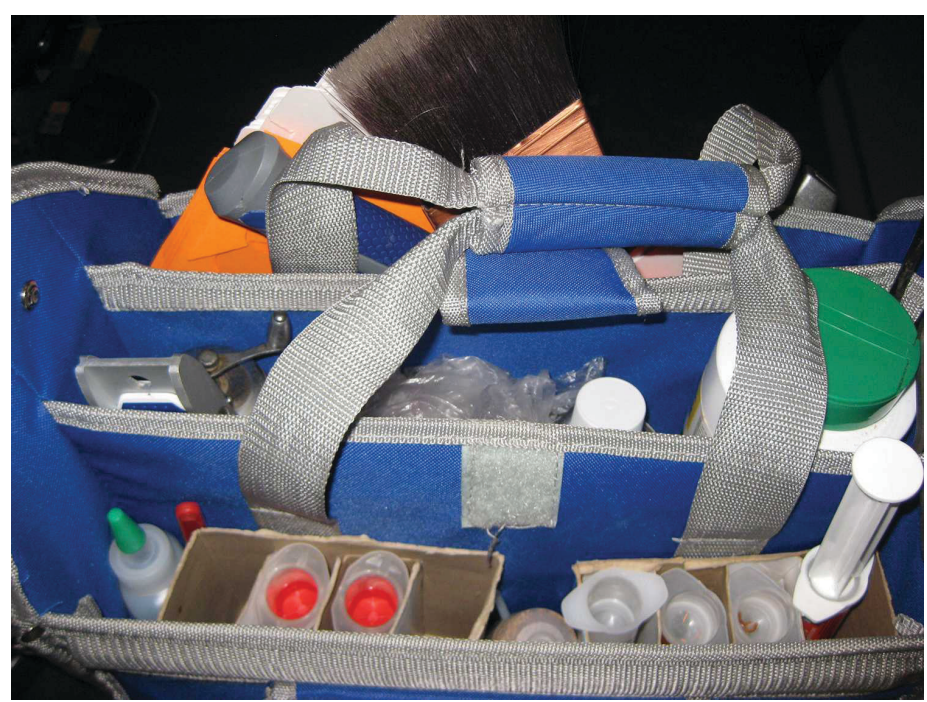

Figure 14. Keep your bait stored separately from products that might contaminate your bait. Do not leave your bait in the lockbox or cab of your truck when it is hot. Heat will degrade your product and make it runny and difficult to apply. This kit is an excellent example of how to keep your bait.

Credits: D. Lisenko, Manatee County Public School kit

\section{WHY USE INSECT GROWTH REGULATORS (IGRS)?}

- IGRs will prevent the normal development of immature cockroaches so they cannot reproduce as adults.

- Gravid female German cockroaches decrease their feeding and foraging significantly while carrying an ootheca (egg case), which means that the probability of gravid females finding and eating enough bait for control is less than other life stages. IGRs cause the ootheca to release prematurely, which results in the female returning to her normal foraging and feeding patterns; thus, increasing the probability of the female finding and feeding on the bait. 
- IGRs are most effective when applied as a crack and crevice treatment to cockroach harborages.

- It may be advisable to place bait close to but not on top of an IGR treatment to avoid the possibility of decreased bait palatability.

- Read the label. Not all IGRs can be used close to food preparation surfaces, and some are volatile.

\section{PRODUCT SELECTION*}

*Product listings are examples, not endorsements.

- Currently there are numerous cockroach baits on the market. They can be evaluated according to: time to kill, active ingredient (AI) class, formulation, and pricing.

- Baits such as Maxforce Impact and Advion ${ }^{\text {ru }}$ Cockroach Bait kill cockroaches in as little as a few hours. These baits can be used for an initial "clean-out" to reduce the pest population quickly.

- Baits such as Vendetta Plus and InTice ${ }^{\text {ta }}$ Roach Bait contain slower-acting active ingredients. These baits are ideal choices in rotations because the cockroaches will live long enough for the bait to secondarily transfer to other cockroaches.

- Most German cockroach baits are gel formulations. Avert Dry-Flowable is the exception. It is a powdered bait (not a dust) that can be used in some situations. A dry-flowable product cannot be used everywhere that a gel bait can, but it is an excellent option in rotation with gel baits. Dry-flowable baits will not dry out and become less palatable as gel baits do.

- The active ingredient class of a bait must also be considered. If cockroaches are resistant to one active ingredient, then they can be resistant to other baits in the same class. However, cross-resistance between classes is also possible, so use monitors to observe carefully how populations are responding.

\section{PRODUCT ROTATION}

Product rotation can be defined as the selection of products containing active ingredients that act on different target sites of a pest. The way in which the active ingredient works at a target site is called the mode of action.

\section{Why is it important to rotate product?}

Product rotation slows down development of insecticide resistance. Insecticide resistance is when cockroaches eat bait but do not die. Insecticide resistance leads to customer complaints, "call-backs," and cancelled contracts. Insecticide resistance in cockroaches has been reported ever since we started doing cockroach control. Bait-aversion is a more recent phenomenon, known of since the 1990s, that can lead to control failures. Cockroach baits can contain sugars such as glucose that make the bait matrix palatable. In some German cockroach populations, glucose triggers "bitter" neuronal receptors to fire and causes cockroaches to avoid the glucose and baits containing glucose. Bait-aversion is a trait that is inherited much like insecticide resistance is inherited and is widespread enough that it should be considered in IPM plans.

\section{How serious is insecticide resistance?}

- If genes conferring insecticide resistance are already present in $>1 \%$ of the population, then noticeable declines in product efficacy could appear within one generation.

- Depending on environmental conditions, a generation can be completed in about 100 days, about the same amount of time for a quarterly pest control service.

- If resistance gene frequencies are higher (50\%), then one generation post-application could lead to a proliferation of uncontrollable German cockroaches

- Avoid "call-backs" by rotating product.

\section{How do I know if the German cockroach population is resistant or bait-averse?}

- Evaluate the efficacy of your treatment.

- If levels A and B (see above) are done satisfactorily and bait placements (level C)are done properly, you should have control.

- If you do not have control, re-check Levels A and B and select product from a different class of insecticide (level C).

\section{How do I create a rotation of different cockroach baits?}

- Use Table 1 to help you select products with different target sites for German cockroaches.

- Find the IRAC Classification column. Rotations should include products with different numbers as indicated by the number preceding the mode of action description.

- By rotating three to six baits with active ingredients from different IRAC classes, you can reduce insecticide resistance and bait aversion. For example, if the German cockroach population you are dealing with is averse to the bait you use on your first visit, but you apply different baits on your second and third visit, most likely the second and third baits will kill the cockroaches that did not eat the first bait. 
- Using different baits at once can increase the probability that cockroaches receive sublethal insecticide doses and actually increase the probability of insecticide resistance and cross-resistance building in populations.

- Put your rotation schedule in an easily accessible location (Figure 15).

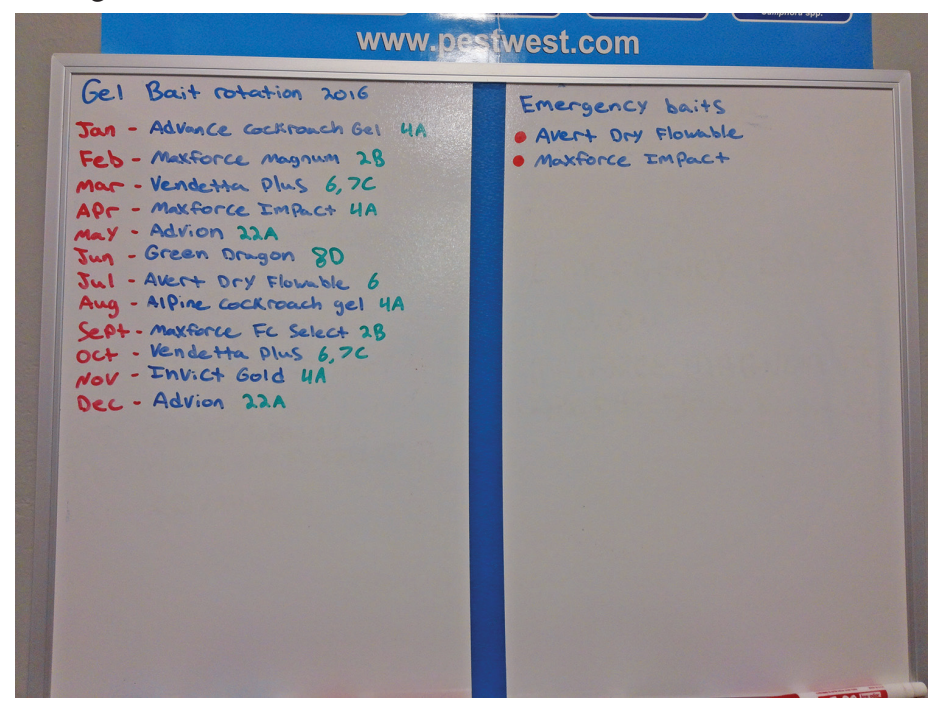

Figure 15. Product rotation schedule in an easily accessible location. Rotation is important to reduce the development of bait aversion and insecticide resistance. Technicians receive one type of bait at the beginning of the month at the same time the previous month's products are collected to ensure that the rotation is being followed. Numbers and letters after products refer to the Insecticide Resistance Action Committee (IRAC) groups that can simplify product selection by chosing products with different IRAC numbers.

Credits: D. Lisenko, Manatee County Public School kit

\section{Level D-Other Treatments}

With the availability of modern baits, IGRs, and sanitation, with an emphasis on the use of HEPA vacuums, there is virtually no reason to use the methods described below. However, they are available and may be offered as an option for German cockroach control. It is important to be aware of some of the unintended consequences of Level D treatments.

\section{WHY WOULD SOMEONE PROPOSE THESE METHODS?}

- They may be perceived as a quick fix. However, consider the total time it takes for preparation (e.g. covering or moving items), the time that employees and children must stay out of the area, and clean up (e.g. washing items in the treatment area) for a properly planned liquid residual application.

- Options include:

- Dusts applied to dry, inaccessible void areas.
- Consider the active ingredient being used and where it is being applied.

- Dusts containing pyrethroids should never be applied to outlets in a cafeteria during lunch. This kind of application can cause cockroaches to flood into the eating area, if there is an active infestation. It also will contaminate an excellent place to apply bait.

- Improperly applied, dusts can become airborne, contaminating off-target sites and non-target organisms, including people. Unnecessary exposure creates increased liability.

- Fogging, baseboard (Figure 16) and surface sprays, and targeted application of a liquid residual product to known harborage areas.

- Fogging is not the same as fumigation and is generally ineffective.

- It is important to note that using a product with repellent properties in an area where bait may be applied will render the bait ineffective because the treatment will contaminate the bait making it repellent and cockroaches will not consume it.

- Many of these treatments cannot or should not be done during operating hours.

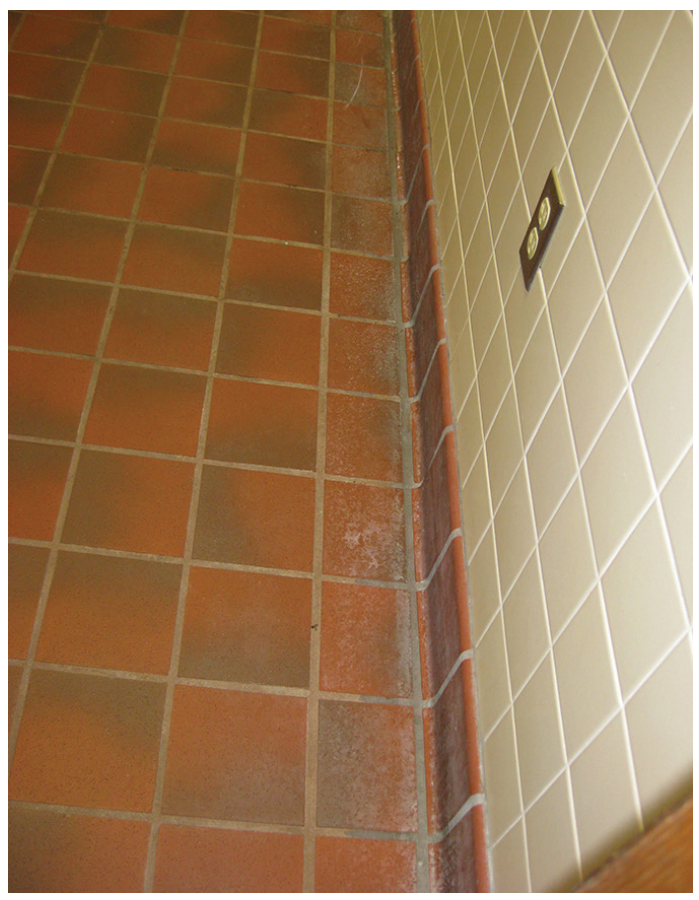

Figure 16. The telltale spray pattern of an ineffective baseboard application. This kitchen was still infested with German cockroaches. 
Table 1. German cockroach baits and their corresponding Insecticide Resistance Action Committee (IRAC) Classes, which can be used to develop product rotation schedules. Product listings are examples, not endorsements, and the table is not designed to be inclusive of all possible products.

\begin{tabular}{|c|c|c|c|}
\hline Product Name & Active Ingredient (AI) & IRAC Classification* / Chemical Class & Formulation \\
\hline Advance $^{\mathrm{TM}}$ Cockroach Gel Bait & Dinotefuran & $4-n A C h R$ agonist; neoticotinoid & Gel bait \\
\hline Advion ${ }^{\circledR}$ Gel Cockroach Bait & Indoxacarb & $\begin{array}{l}22 \text { - Sodium channel blocker; } \\
\text { oxadiazine }\end{array}$ & Gel bait \\
\hline Alpine ${ }^{\circledast}$ Cockroach Gel Bait & Dinotefuran & $4-n A C h R$ agonist; neoticotinoid & Gel bait \\
\hline Avert ${ }^{\oplus}$ Dry Flowable & Abamectin & $\begin{array}{l}6 \text { - Chloride channel activator; } \\
\text { avermectin }\end{array}$ & Dry flowable \\
\hline InTice ${ }^{T M}$ or Magnetic ${ }^{T M}$ Roach Bait & Boric acid & 8 - Miscellaneous; borate & Gel bait \\
\hline InVict Gold ${ }^{T M}$ Cockroach Gel & Imidacloprid & 4-nAChR agonist; neoticotinoid & Gel bait \\
\hline Maxforce $^{\circledast}$ Impact & Clothianadin & $4-n A C h R$ agonist; neoticotinoid & Gel bait \\
\hline Maxforce ${ }^{\circledast}$ Magnum & Fipronil & 2 - GABA antagonist; phenylpyrazole & Gel bait \\
\hline Maxforce ${ }^{\circledR}$ FC Select & Fipronil & 2 - GABA antagonist; phenylpyrazole & Gel bait \\
\hline Vendetta ${ }^{\circledR}$ Cockroach Gel Bait & Abamectin & $\begin{array}{l}6 \text { - Chloride channel activator; } \\
\text { avermectin }\end{array}$ & Gel bait \\
\hline Vendetta ${ }^{\circledast}$ Plus & Abamectin + Pyriproxyfen & $\begin{array}{l}6 \text { - Chloride channel activator; } \\
\text { avermectin } \\
7 \text { - Insect growth regulator }\end{array}$ & Gel bait \\
\hline
\end{tabular}

